\title{
A Evangelização Inculturada na Amazônia
}

Incultured Evangelization in the Amazon

Denilson Geraldo ${ }^{1}$

\section{0 diálogo social e cultural na Amazônia}

A Exortação apostólica pós- sinodal Querida Amazônia traz alguns elementos presentes nos capítulos I e II, denominados como sonho social e sonho cultural. Inicialmente, Francisco afirma que essa Exortação não substitui o Documento Final do Sínodo, mas é uma síntese de suas grandes preocupações sobre a região Amazônica que é formada por nove países: Brasil, Bolívia, Colômbia, Equador, Guiana, Perú, Suriname, Venezuela e Guiana Francesa.

No debate internacional, a abordagem ecológica sobre a Amazônia exige sempre a abordagem social, considerando principalmente clamores dos pobres. O comércio da madeira e a indústria de minérios atentaram diretamente contra as comunidades indígenas e ribeirinhas, causando o movimento migratório dos indígenas para as periferias das cidades. Neste sentido, o clamor também vem dos pobres moradores no interior das cidades

\footnotetext{
${ }^{1}$ Doutor em Direito Canônico pela Pontifícia Universidade Lateranense de Roma; Professor do Instituto Superior de Direito Canônico de Santa Catarina, do Instituto de Direito Canônico de Londrina e da Faculdade de Direito Canônico São Paulo Apóstolo. Diretor do Istituto San Vincenzo Pallotti (Roma). Editor da Revista Scientia Canonica e da Rivista Apostolato Universale.
} 
amazônicas e é preciso indignar-se, como se indignaram Moisés (cf. Ex 11,8$)$ e o próprio Jesus (cf. $M c$ 3, 5), contra um novo colonialismo revestido de globalização.

Todavia, o Papa nos convida a construir redes de solidariedade e desenvolvimento, aprendendo com os povos indígenas o senso da fraternidade, para sanar os danos causados pela emigração para as cidades e, consequentemente, a desintegração e o desenraizamento cultural.

Cristo redimiu o ser humano inteiro para recompor em cada um a sua capacidade de se relacionar com os outros. Na Encíclica Laudato si', há seis anos de promulgação, nos foi apresentado que tudo está relacionado. Todavia também o estado de saúde das instituições de uma determinada sociedade é condicionado pelo ambiente. Neste sentido, os povos amazônicos não são alheios à corrupção, mas tornam-se suas principais vítimas. Tais práticas de corrupção também podem entrar na Igreja mediante a participação nas redes de corrupção política e na aceitação de doações que não tenham uma procedência legal e honesta.

Podemos evitar a instalação de um ambiente de corrupção se o diálogo, como discípulos e missionários, for iniciado pelos últimos, pelos pobres. Esses não são apenas interlocutores para o convencimento, mas são os principais interlocutores e deles devemos aprender escutando.

Essa é uma obra educativa que implica em "cultivar sem desenraizar, fazer crescer sem enfraquecer a identidade, promover sem invadir" (n. 28). Tais gestos protegem as culturas presentes na Amazônia (mais de cento e dez povos indígenas considerados erroneamente de selvagens ou não civilizados) que ainda não foram ouvidas e que correm o risco de desaparecer (n. 29).

Os jovens indígenas são convidados a assumir as raízes, pois das raízes provém a força que faz crescer, faz florescer e faz frutificar, recebendo dos mais idosos a sabedoria cultural. Nesta perspectiva, os grupos humanos poderão ter cosmovisões que se enriquecem e, mesmo as cidades, serão lugares de encontro e não um palco doloroso 
de descarte. Deus se manifesta em um território, daqui o conceito de Igreja local, e reflete sua beleza nos diferentes grupos humanos, provocando uma síntese vital com o ambiente circundante.

Considerando, infelizmente, a possibilidade de desaparecimento de algumas culturas, alguns povos começaram a escrever suas histórias e descrever o significado dos seus costumes. É magnífico reconhecer que diversas expressões artísticas foram influenciadas pela água, pela floresta e pela vida que se movimentam. Em outras palavras, as etnias presentes na Amazônia desenvolveram um tesouro cultural em conexão com a natureza, com forte sentido comunitário, e se deram conta das sombras da cultura industrializada com seu suposto progresso (n. 36).

Todavia, a diversidade cultural não pode representar uma barreira, mas uma ponte, pois a identidade e o diálogo não são inimigos. Do mesmo modo como se afronta o tema da migração no ocidente, também aqui, uma cultura pode tornar-se estéril quando se fecha em seus próprios limites. O Papa não defende um "indigenismo absoluto", mas um diálogo cultural e social que deve interessar a todos porque a riqueza da cultura indígena interessa também ao ocidente e vice-versa. O lugar por excelência para esse diálogo é a família que sempre contribuiu para manter viva a cultura.

Concluindo os capítulos sobre o sonho social e o sonho cultural, o Papa recorda o conceito de ecologia humana de Bento XVI, quando dizia que, "ao lado da ecologia da natureza, existe uma ecologia que podemos designar humana, a qual, por sua vez, requer uma ecologia social. E isto requer que a humanidade (...) tome consciência cada vez mais das ligações existentes entre a ecologia natural, ou seja, o respeito pela natureza, e a ecologia humana" (n. 41). Afinal, tudo está interligado. 


\section{A conversão ecológica na Querida Amazônia}

O capítulo terceiro da Exortação é um convite a contemplar um sonho ecológico para os povos que vivem nesta região, bem como para toda a humanidade.

Inicialmente, recordamos a Encíclica Laudato Sì ao tratar da ecologia integral que com grande repercussão em 2015 em razão de uma visão humana, social e eclesial da ecologia, indicou novos parâmetros para a educação e para o aprofundamento da teologia da criação. O ponto central para a humanidade, considerou a Laudato $\mathrm{Si}$, é a urgente necessidade de adotar um estilo de vida que não seja conforme o consumismo que gera a poluição do planeta, a ausência de água potável, a perda da biodiversidade, a deterioração da qualidade de vida humana e a degradação social. Na realidade, é decisivo alterar o modus vivendi para que haja também uma mudança na condução do poder político, econômico e social em favor de uma ecologia integral.

$\mathrm{Na}$ Exortação Apostólica Querida Amazônia a realidade cultural requer uma relação estreita do ser humano com a natureza, abrindo-se ao conceito de ecologia humana e de ecologia social, demonstrando que tudo está interligado. Ora, o cuidado das pessoas e o cuidado dos ecossistemas são inseparáveis, de onde resulta que a floresta não é um recurso para explorar, mas um ser vivente com a qual é necessário manter relações.

Quando se elimina a floresta, entra aqui a visão de exploração e não de relação. A floresta não será substituída por outra floresta, mas se transformará em território desértico e pobre em vegetação. Os inúmeros recursos, que poderiam ser indispensáveis para a cura de doenças, desaparecem. Com efeito, os interesses particulares locais e internacionais, sejam empresariais sejam políticos, não deveriam ser colocados acima do bem da Amazônia e da humanidade.

A solução para a problemática ecológica não está na internacionalização da Amazônia que representaria a perda de autonomia política sobre o território dos nove países que compõem a 
Amazônia, porém a solução exige a responsabilidade dos governos nacionais com maior urgência e decisão. Contudo, os organismos internacionais e as organizações da sociedade civil devem trabalhar de forma crítica, sensibilizando os povos nativos e a humanidade, para que os governos cumpram o próprio dever. A responsabilidade dos governos nacionais e locais, de preservar o meio ambiente e os recursos naturais dos seus países, não é delegável. Os interesses locais e internacionais também têm a responsabilidade de colaborar para a prática de uma ecologia integral.

Nesta relação política e econômica é necessário conjugar a sabedoria ancestral dos povos presentes na região amazônica com os conhecimentos técnicos contemporâneos para intervir de forma sustentável no território. Assim, é um direito dos povos nativos receber a "formação básica, a informação completa e transparente dos projetos, com a sua amplitude, os seus efeitos e riscos, para poderem confrontar esta informação com os seus interesses e com o próprio conhecimento do local" (n. 51).

Nesta relação entre sabedoria ancestral e conhecimentos técnicos contemporâneos é urgente a criação de um "sistema normativo que inclua limites invioláveis e assegure a proteção dos ecossistemas" (n. 52), pois é necessária a defesa do direito dos mais fracos. Nesse caso, as novas formas de poder derivadas dos conhecimentos técnicos podem destruir os povos nativos da Amazônia, não só pela política, mas também por um direito que não assegure a relação entre sabedoria ancestral e conhecimentos técnicos.

O Papa Francisco alerta para o perigo de que a consciência se torne insensível e, se nos detivermos na superfície, "pode parecer que as coisas não estejam assim tão graves e que o planeta poderia subsistir ainda por muito tempo nas condições atuais. Este comportamento evasivo serve-nos para mantermos os nossos estilos de vida" (n. 54) e não buscarmos uma conversão ecológica que é ao mesmo tempo humana e integral. 
A conversão é uma mudança e, aprendendo com os povos nativos, a humanidade é convidada a contemplar a Amazônia e não apenas analisá-la; podemos amá-la e não apenas usá-la; podemos nos sentir unidos a ela e não só defendê-la. Trata-se de uma relação existencial, jurídica, humana e espiritual com a Amazônia para apreciar sua beleza e para estar em comunhão com os povos nativos e com a criação. Deste modo, afirma o Papa Francisco, "nós, os crentes, encontramos na Amazônia um lugar teológico, um espaço onde o próprio Deus Se manifesta e chama os seus filhos" (n. 57).

A ecologia integral incluirá sempre a educação e a exigência de novos hábitos menos vorazes, mais serenos, mais respeitadores, menos ansiosos, mais fraternos nas pessoas e nos grupos humanos. Quando o coração da pessoa está vazio tanto mais necessita consumir e não aceita que a realidade lhe coloque limites. $\mathrm{O}$ consumismo não educa para a relação fraterna, mas para o domínio que gera crises sociais e familiares, revelando um egoísmo que pode justificar a morte do irmão para satisfazer os interesses pessoais. É necessária uma educação para o diálogo, para o direito e para a fraternidade humana que saiba reconhecer em cada cultura um valioso patrimônio para toda a humanidade.

\section{A inculturação eclesial na Amazônia}

O sonho eclesial de Francisco é a inculturação eclesial na Amazônia como uma autêntica opção evangélica pelos mais pobres que impele à promoção humana e à defesa dos direitos humanos, para propor a amizade com o Senhor pela fé católica. O direito ao anúncio do Evangelho é universal e sem tal anúncio as estruturas eclesiais transformam-se apenas em uma Organização Não Governamental, não colocando em prática o fundamento da missão eclesial: "Ide pelo mundo inteiro, proclamai o Evangelho a toda criatura" (Mc 16, 15). De fato, o anúncio do Evangelho e o amor fraterno constituem a grande síntese da Boa Nova, que não se pode deixar de propor na Amazônia. 
Consequentemente, estará se desenvolvendo de modo permanente e necessário o processo de inculturação, pois "a graça supõe a cultura, e o dom de Deus encarna-se na cultura de quem o recebe" , o que implica em anunciar o Evangelho para uma determinada comunidade. A própria Igreja se enriquece com aquilo que o Espírito, misteriosamente, semeou na cultura, realizando uma nova síntese com essa cultura ${ }^{3}$. Afirmar que o Espírito Santo traz o novo significa recriar, a partir do inesgotável depósito da fé, a unidade eclesial com a cultura e com os laços de fraternidade da família humana.

Todavia, para uma inculturação do Evangelho na Amazônia, é necessário escutar a sabedoria ancestral dos povos indígenas, sua relação harmoniosa entre as necessidades humanas com austeridade e com simplicidade, abrindo-se para a dimensão familiar, comunitária e ecológica. A sabedoria indígena apresenta uma interconexão e uma interdependência da criação que é capaz de reeducar a pessoa urbana, superando o consumismo ansioso e o isolamento, pois “é o Senhor que reina sobre a criação sem perder as suas chagas transfiguradas e, na Eucaristia, assume os elementos do mundo dando a cada um o sentido do dom pascal" (n. 74).

A inculturação é, necessariamente, social e caracteriza-se por uma defesa dos direitos humanos, reconhecendo a unidade entre a evangelização e a promoção humana. Para tanto, é urgente a formação sobre a doutrina social da Igreja que forme a identidade eclesial amazônica, unindo-se com a piedade popular e com os espaços de fraternidade.

$\mathrm{Na}$ verdade, a imensa extensão territorial da região panamazônica, a grande diversidade cultural, os graves problemas sociais, a migração constante, também como um corredor para outras regiões, e a própria opção de alguns povos de se isolarem exigem uma resposta corajosa da Igreja para a evangelização inculturada que requer sempre a promoção humana pela defesa dos direitos humanos.

\footnotetext{
${ }^{2}$ Evangelii Gaudium, 115 .

${ }^{3}$ Evangelii Gaudium, 129.
} 
A fé cristã inculturada na vida dos povos nativos encontra nos Sacramentos uma unidade entre a graça e a criação, na qual a natureza é elevada para ser instrumento da graça. A Eucaristia "une o céu e a terra, abraça e penetra toda a criação (...) e é fonte de luz e motivação

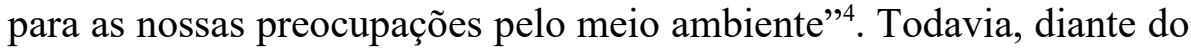
esforço de inculturação da liturgia, colocando ao centro a celebração do domingo ${ }^{5}$, constata-se que pouco se fez pelos povos indígenas. É necessário ouvir o clamor das comunidades privadas da Eucaristia dominical por longos períodos, com ministros ordenados que possam compreender a partir de dentro as culturas amazônicas.

O conceito teológico que relaciona o presbítero com "Cristo cabeça" (n. 87), significa que Cristo constitui o presbítero como fonte da graça "porque tem o poder de comunicar a graça a todos os membros da Igreja" seja pela celebração da Eucaristia, fonte e cume de toda a vida cristã, seja pela celebração do sacramento da penitência (n. 88). Na Amazônia, tendo em vista uma evangelização inculturada, o laicato tem a missão de anunciar a Palavra, de ensinar, de organizar as comunidades, de celebrar alguns Sacramentos, mas as comunidades precisam também da celebração da Eucaristia. Na América Latina se convida à oração pelas vocações sacerdotais missionárias e, ao mesmo tempo, se recomenda vivamente que a formação inicial, bem como a formação permanente dos presbíteros, possibilite dialogar com as culturas amazônicas.

Para o crescimento das comunidades na Amazônia, poderia haver um maior número de diáconos permanentes, as religiosas e os próprios leigos poderiam assumir maiores responsabilidades que supõem um processo de maturação - bíblica, doutrinal, espiritual e prática - com distintos percursos de formação permanente. Uma cultura eclesial própria, marcadamente laical, exige da Igreja um esforço para conseguir uma presença capilar que só é possível com um

\footnotetext{
${ }^{4}$ Laudato Si, 236.

${ }^{5}$ Sacrosanctum Concilium, 37-40, 65, 77, 81.

${ }^{6}$ São Tomás de Aquino, Summa Theologiae III, q. 8, a. 1, resp. 
incisivo protagonismo dos leigos (n. 94). De modo particular as comunidades de base, a REPAM e outras associações podem oferecer uma grande contribuição para consolidar o que solicitou a Assembleia dos bispos em Aparecida: "estabelecer, entre as Igrejas locais de diversos países sul-americanos que estão na bacia amazônica, uma pastoral de conjunto com prioridades diferenciadas"7.

O trabalho evangelizador das mulheres foi capaz de transmitir a fé por decênios, sem a presença dos presbíteros. A maior participação feminina na Igreja, afirma Francisco, "se lhes fosse concedido acesso à Ordem sacra (...), levar-nos-ia a clericalizar as mulheres, diminuiria o grande valor do que elas já deram e sutilmente causaria um empobrecimento da sua contribuição indispensável" (n. 100). As mulheres prestam à Igreja a sua contribuição segundo o modo que lhes é próprio, que não se limita a uma impostação funcional, mas considera importante a presença feminina na estrutura da Igreja, esposa do Senhor.

A situação atual exige que se estimule o aparecimento de serviços e de carismas femininos que deem resposta às necessidades específicas dos povos amazônicos com funções, que não requeiram a Ordem sacra, mas com estabilidade, com reconhecimento público e enviadas pelo bispo. Assim, as mulheres terão uma presença real e efetiva na organização, nas decisões e na direção das comunidades, mas sem deixar o estilo próprio do seu perfil feminino. Esse é o sonho eclesial de Francisco.

\footnotetext{
${ }^{7}$ V Conferência Geral do Episcopado Latino-americano e do Caribe, Documento de Aparecida (29/VI/2007), 475.
} 